\title{
Being in limbo: The experience of critical illness in intensive care and beyond
}

\author{
Agness C. Tembo ${ }^{1,2}$, Vicki Parker ${ }^{3,4}$, Isabel Higgins ${ }^{1,3}$ \\ ${ }^{1}$ University of Newcastle, Newcastle, Australia \\ ${ }^{2}$ Newcastle Private Hospital, New Lambton Heights, Australia \\ ${ }^{3}$ University of New England, Armidale, Australia \\ ${ }^{4}$ John Hunter Hospital, New Lambton Heights, Australia \\ Email: Agness.Tembo@studentmail.newcastle.edu.au
}

Received 12 April 2012; revised 16 May 2012; accepted 28 May 2012

\section{ABSTRACT}

Critical illness is a sudden traumatising lived experience that affects the sufferer and their family throwing them into a crisis situation [1,2]. It is disruptive and alienating. Critically ill patients emerging from unconsciousness often suffer from confusion that could be momentary or lasting. There is an increasing number of critical illness survivors in intensive care units (ICU) ${ }^{1}$ with numerous life changing ongoing physiological and psychological sequelae from critical illness and ICU hospitalization, with inadequate ongoing treatment for ICU survivors. Medicalised accounts of critical illness fail to recognise the significant impact on the person, their embodied sense of self and their ability to move on with their life after they leave hospital. The main purpose of this study was to explore the experience of critically ill patients in ICU and beyond. This phenomenological study describes what it was like for twelve people to experience critical illness in ICU and in the months after discharge. The finding was that critical illness is an acute life threatening event with long lasting effects which translate into temporal and biographical disruption, imprisonment by the ICU and its therapies and being trapped in an alien body that is plagued by uncertainty and long lasting conditions arising from the critical illness and the ICU therapies. Critical illness survivors are left in a state of limbo characterised by a struggle to reclaim their precritical illness ICU identity and uncertainty about their future. Hence an overarching theme of being in limbo under which three major themes of 1) disruption; 2) imprisonment and 3) being trapped were generated from the study.

Keywords: Critical Illness; Intensive Care; Mechanical Ventilation; Daily Sedation Interruption

${ }^{1}$ ICU—Abbreviation for Intensive Care Unit.

\section{INTRODUCTION}

Numerous studies have examined the experience of critical illness [3-5]. Anecdotal evidence suggests that the experiences of patients have been consistent over time [6] despite advances in technology and changes in ICU practice. Attempts to make the experience of critical illness better in ICU have also been made. This is evidenced by the major technological advances in mechanical ventilation like early tracheostomy and innovations in ICU practices particularly sedation practices. These efforts have mostly been directed at reducing ventilator time and ICU length of stay (LOS) [7,8], promoting comfort, wakefulness and the ability of patients to interact [9], prevention of complications associated with continuous deep sedation such as prolonged mechanical ventilation $[8,10]$ and ventilator acquired pneumonia $[8$, 10]. In addition sedation practices like DSI are associated with short ventilator and ICU stay [10]. These innovations and technological advances have led to increasing numbers of ICU survivors [11]. However, the benefits of these innovations particularly DSI have not been examined through the eyes of the critically ill patients nor has the meaning of surviving such an experience been fully explored. So far only one study [12] has examined the long term impact of DSI on the lived experiences of patients who have undergone the same.

Approximately 130,000 adults are admitted to Australian ICUs each year $[13,14]$. Nevertheless this high survival rate has led to a burden on the patients, their families, communities and most of all the health care system [14]. However, the cost and burden is difficult to quantify because the number of critical illness ICU survivors requiring ongoing care is annually increasing at a rate of $8.8 \%$ [15]. It is also clear that in many instances patients and their families face major challenging, difficult and often life changing experiences [16] during and after a critical illness in ICU. Evidence suggests that the burden of critical illness after ICU is greater $[11,17,18]$. Hence, 
this study examines the experience of critical illness in and beyond ICU in the context of the technological advancements and innovations in ICU practices that have taken place over the past decade.

Australia has an $86 \%$ adult critical illness survival rate [14]. However most of these survivors have physical and psychological sequelae that continue to afflict them for most of their life after ICU $[14,18]$. Despite the growing knowledge and concern about survivorship sequelae there are no established models of care that systematiccally address this issue particularly in Australia and interventional studies are also few [19]. Some researchers argued that patients with delusional memories, depression and anxiety had poorer HRQoL and took longer to return to work [20]. Other researchers found that patients' HRQoL in relation to mobility, eating, breathing, vitality and common activities was significantly declined even though the patients managed to return to similar kind of life style $[15,19]$.

\section{STUDY DESIGN AND METHOD}

In-depth face to face interviews were conducted with twelve participants at two weeks after ICU discharge and at six to eleven months later. In line with hermeneutic phenomenology thematic analysis using van Manen's six dynamic interplay activities was used to interpret the data about the lived experience of being critically ill in ICU [21]. Phenomenology believes in starting by reawakening the basic experience of the world of which science is the second-order of expression [22]. The phenomenological method was aimed at re-awakening the participants' lived experience of critical illness in an ICU and how it impacted them afterwards. The approaches used were designed to enhance understanding experiences based on the descriptions of the participants.

\subsection{Participant Selection}

Participants in this study were recruited from a tertiary referral hospital ICU in New South Wales Australia. Participants were recruited with the assistance of the ICU Nurse Educator, the Clinical Nurse Consultant for Research, the Clinical Nurse Consultant in Quality Improvement, the ward Nursing Unit Managers (NUMs) and their staff. Both men and women who fulfilled the general and essential criteria for recruitment into the study were approached. Essentially the participants had to have been critically ill in ICU and mechanically ventilated for at least 24 hours with a good prognosis to ensure completion of the research by not dying during the research process. To ensure true informed consent and avoid misunderstanding in the research process, the participants needed to be able to speak English and had to be between eighteen years old and above. It was assumed that the participants were interested in sharing their experience if they signed the consent form after they had read the information letter. Once the consent was obtained, the recruiters forwarded the consent to the researcher who then contacted the participants and arranged for the face to face interviews. People with cognitive impairment and poor prognosis were not recruited in the study.

\subsection{Data Collection}

Data collection was conducted through in-depth face to face as per hermeneutic phenomenological tradition [21]. In-depth interviews were conducted in participants' homes or place of preference where both the participants and the researcher were safe and comfortable. To capture the experience as raw and as fresh as possible at two weeks and to discover how critical illness and ICU hospitalisation had impacted on the continued existence of the participants up to eleven months later. The interviews were audio taped. Each interview lasted between 30 - 60 minutes. A field diary in which the researcher recorded events of the day during data collection was kept. Events of the day included how the researcher's mood was affected by the participants' narratives and how she dealt with her feelings, the demeanour of participants during the interview and anything that could not be tape recorded. The questions asked were, "In your own words, can you tell me what it was like to be critically ill in ICU?" "In your own words can you tell me what it was like to be critically ill in intensive care?"; "What does it mean to have been critically ill in ICU?” These questions helped to meet the aim of the study which was to describe the experience of critically ill patients in ICU. Data was transcribed and accuracy of data transcripts was verified by the participants.

\subsection{Ethical Considerations}

Ethics was approved by the Hunter New England Health Research Committee and the University of Newcastle's Human Research Committee in December, 2007.

\subsection{Data Analysis}

Data analysis was conducted using thematic analysis as per van Manen's six dynamic interplay activities [21]. This involved reading and reflecting on the individual transcripts, recollecting the participants' demeanor during data collection, formulating themes and writing and rewriting - working the text or rather crafting the text [21]. Through this process a conversational relationship was developed with research question that led to the results.

\section{RESULTS}

The overarching theme that captures the nature of the 
experience is being in Limbo with three major themes that have got subthemes of their own. Being in limbo was essentially characterised by disruption, imprisonment and the pervasive presence of death throughout the trajectory of the participants' critical illness journey.

\subsection{Being Disrupted}

Being disrupted was a state of limbo in which the participants' lives were suspended between life and death while they were unconscious. It was essentially being "absent" from the world.

"I was blacked out, I don't remember anything... I only thought I was ventilated for four hours for some reason, I don't know where that figure came from, that I thought I was only asleep for four hours-ventilated for four hours but I was asleep for three days... I didn't know what was going on and I didn't know how long I'd been there and I didn't know what was happening."

(Rosie 1st Int.)

Many participants believed they should have had memories of their critical illness situation, or at the very least dreams or supernatural encounters such as seeing bright lights or going to heaven (Keith 1st Int.) or other near death experiences. In the following exemplar, Moira describes the strangeness of not having her ideas realised while she hovered between life and death:

"No dreams, no going to heaven that's strange, I've heard people say they know when they're unconscious, but I didn't ... I thought I would have an experience where I would go to heaven ... but I didn't ...So having had no supernatural experience, it was just as if you were floating all of the time, lifeless, but no experience, no... It was strange."

(Moira 1st Int.)

Trying to figure out was a feature of the participants' initial preoccupation of being fully conscious. Most of the participants were unsettled by not knowing and not remembering what had gone on or how things had happened to them.

"Trying to figure out how long I was there for and who, who was coming in and out of the room and which, you know, where was I and things like that, trying to figure out what happened in that time when I was blacked out. I didn't like not knowing what was going on and the tube in my neck, I don't know how it got there."

(Rosie 1st Int.)

Some participants described the period they were blacked out as lost time. Because time is part of how participants live and know themselves in the world, losing time created a sense of discontinuous existence for them. As Keith said;

Others found it strange to lose so much time.

"But I don't remember the family talking to me or staying with me or nurses or doctors doing anything...
And grandson came in and he was kissing and cuddling and talking to me and I love him dearly, but I don't remember that... I would've had liked to have known that the family were there and caring and loving (and they're always caring and loving, but this was extra special)//it is strange to lose so much time".

(Moira 1st Int.)

\subsection{Being Imprisoned}

Being imprisoned depicts the sense of limbo in which the participants experienced restriction and threat to their life during the wakefulness phase of their ICU stay. This theme further shows how the participants fought to stay alive and to keep in touch with the lived other. The main source of imprisonment and existential threat emanated from the endotracheal tube itself which was meant to be life giving for the participants.

Fighting for Life elucidates the descriptions and the meaning the participants attached to the experience of trying to save themselves from the life threatening events that they faced in ICU.

"The tube was a big thin//I couldn't breathe with it. I wanted to pull it out//And I kept trying to pull the tube out of my mouth I felt like I just couldn't breathe with it in there it was gagging me and I just wanted it out. I just wanted to pull it out. I can remember feeling that I wasn't getting enough breath I thought I was going to suffocate. My fighting spirit kicked in I tried to pull it out”

(Monika 1st Int.)

Being Voiceless describes what it was like for the participants to be unable to speak.

"When I went to talk... I just couldn't talk. And I thought, 'what's happened to my throat,' like it issomeone's taken your voice off you. I had a lot of questions to ask, but I couldn't ask... you can't ask a question because you've got this thing jammed in your throat and you want to ask, but you can't ask and no-one's telling you the answers that you want to know."

(George 1st Int.)

\subsection{Being Trapped}

Being trapped portrays the participants' experience of their "disabled" post ICU self and their struggled to regain a sense of their previous identity.

Longing for the past was fundamental to the participants for various reasons but most of all for the purpose of interacting with others and for maintenance of their old self.

Being forgetful highlights the difficulties associated with getting on with life when they remain forgetful and have difficulty planning and carrying out tasks.

"I used to keep appointments but I forget a lot of 
things now. I forget meetings I've got to go to. I just forget all about things I've got to do."

(Erick 2nd Int.)

Moira's account was intriguing:

"I had to stop and think what my name was and I thought, you silly old woman, been married 58 years, you should know... So it's just strange what does happen... Well you're born and you're given a name aren't you? And you've had that all your life... Some days, if someone knocked on the door and said to me, 'Mrs. X' I'd look at them blank and think now, who's that? That is a horrible feeling."

(Moira 1st Int.)

Longing for normal sleep portrays how the participants continue to endure sleeplessness and the meaning it holds for them.

"No reason why whether it was the medication or the surroundings or what it was, just couldn't get back to sleep. I just couldn't... Like last night I think I woke up about half past 12 or something like that... Same thing I had even when I took sleeping tablets. You take one and I'm lying awake at the same time the rest of the nightno sleep, so no point taking them. I was told I shouldn't be taking them anyway... It so desperately wants to sleep. Becomes annoying [sic]. And you don't know why. You can't understand it...One day I'll get back to a normal nice sleep".

(Keith 1st Int.)

Waiting for the familiar and reliable voice describes the experience of having to live with a different sounding voice and one that cannot be relied on when needed to speak. Most of the older participants in this study had a different voice or no voice at all. They spent a large amount of their post hospital time at least up to the time they were interviewed, waiting for their voice to become normal and reliable again. For most of them, their voices were hoarse and at times were reduced to just a whisper. They felt strange and that they had lost their identity:

"So there we are-in limbo. Oh, it is annoying. You know, you're talking softly and people can't understand or hear you. You've got to sort of repeat yourself and you know that it's not your normal voice and I'll get that one day. They say its three to four months (oh God!) but it is so annoying for yourself because you haven't got your normal voice; you can't talk normal to people and they can't understand you a lot of the times; you're talking too softly. That makes you become frustrated. The wife said, 'can't understand what I'm saying or hear.' Give me time. I'll talk properly, one day//Hopefully, one day too. I'll be free."

(Keith 1st Int.)

\section{DISCUSSION AND CONCLUSION}

The most striking finding of this study is the continuing impact of the critical illness and ICU treatment experience hence the notion of being in limbo. Of concern is that phenomenon is not new. The distressing impact of being critically ill in the high technological environment of ICU has been highlighted before $[3,5,23,24]$ and the experience of being mechanically ventilated has featured in other studies $[25,26]$. Others have identified difficultties associated with communication and the devastating impact on patients as they try to make themselves heard and understood $[23,24,27]$. Disturbances of consciousness such as no memory recall and delusional memories have also been highlighted $[6,28]$ this means that there is something amiss that needs to be identified in order to change the experience of critical illness in ICU for the better.

Similarly, the participants' reports of little or no recollection of their ICU experiences have been reported in literature $[6,25,28,29]$. This study's finding that disrupttion causes fear, anxiety and vulnerability in critically ill patients in ICU is consistent with an earlier study [25]. This existential disruption is concerning because it robs people of their coherence and certainty in the world.

Being tied to a bed, being unable to move, breathe and speak are findings which I discussed under the themes of bound and drowning, fighting to breath and being voiceless in Chapter Five. The finding of being bound and drowning in this study is supported by other studies [3, 25] studies whose participants described being unable to move [25], being tied down [3], trying to free themselves from restraints and fighting the ICU staff [3]. The participants' response of fighting to be free is consistent with the above mentioned studies. For the participants in the present study, being bound evoked feelings of fear and a strong presence of death. Unlike studies in which the participants physically fought the ICU staff [3] the participants in this study did not but attempted to free themselves from restraints and tubes and in the process they became agitated, uncooperative and profoundly fearful. This is not surprising as the array of ICU equipment, its strange exclusionary. Its restrictive nature [3] emphasises the imprisonment for the people. It is not known whether it is the technology or its mode of application that evokes this experience. However, the strangeness of the technology particularly when it is perceived as a foreign appendage to one's body $[3,24]$ that serves to alert others of every slight movement or change in the monitored body function is distressing and imprisoning. Feelings of imprisonment can lead to forced compliance and passivity for some patients so as to avoid being sedated again as Liam said I just had put up with it and lie still because I was afraid that if I became obnoxious I would be knocked out again. However other studies have posited that technology and the ICU staff are associat6ed with security for some patients [24,25]. Feelings of im- 
prisonment and powerlessness (loss of control) can perpetuate forced dependency and "capitulation" as evinced in this study-being at the mercy of others, being watched. This confirms the notion of vigilance and invisibility in the technological environment of ICU where the gaze of the ICU staff reduces the patient to parts and organs that are measurable and forget the subjective needs of the patient.

Being in the dungeon is a theme that elucidates the participants' descriptions of how they were isolated from the rest of the world. Being at the mercy of the ICU staff meant that the ICU equipment and its staff controlled the sustenance of their life. The participants had to call upon their survival instincts to carry them through their ordeal. At the same time the participants in this study realised that things could change depending on the circumstances as one participant said; you have got to do as you are told because they just saved your life/l They have got you plugged to machines and it is in their hands (Ian). This kind of helplessness can evoke feelings of degradation where patients feel like objects [3,25].

This study has shown that critical illness and ICU hospitalisation impact the long term experiences of patients. What is lacking are effective systematic models of care that can provide continued care and support for critical illness ICU survivors. The need to develop models of care with guidelines that incorporate follow up care and ongoing support is urgent at least in the Australian context. Explanation and legitimation of critical illness survivorship needs to be included in routine care beginning in ICU and following through to services such as ICU follow up clinics and outreach models of care. Health professionals need to consider the impact of various practices and procedures on the well being of patients, not just in the short term but in the long term. Coherence is fundamental to our existence hence promotion of patient diaries at a larger scale as a means of dealing with disruption will help provide continuity in critically ill survivors. Similarly every effort to reduce the distress emanating from the use of restraints that bind and imprison critically ill a patient in ICU needs to be made to promote humane experience in ICU.

The failure of advanced technology and innovations in ICU practices lies in the increasing number of critical illness ICU survivors with negative sequelae that is placing a burden on the survivors, families and the health care system. Hence models of care across the critical illness trajectory that will include follow up pathways including physical (particularly speech therapy as evidenced in this study), cognitive and mental support, sleep clinics and rehabilitation centres need to be established. Additionally community programs such as support groups for critical illness survivors which may help them to actualise their new identity are needed. Finally, the partici- pants' heightened sense of finitude beckons us to shield patients from witnessing other patients dying and to ensure that fears about dying are addressed with patients before or shortly after discharge from ICU.

To date, there are few examples of post ICU services that provide ongoing care and assessment of the need for referral to services such as counseling, sleep clinics or physiotherapy. This has been recommended elsewhere [20,30]. Strategies include telephone follow up and/or post ICU clinic [28]. Although some programmes of this nature have failed elsewhere [31] revision of these programmes could yield better results. Indeed inclusion of family members would improve outcomes. Each unit needs to examine its own context and work towards a sustainable model of follow-up. More emphasis on comprehensive physical medicine and rehabilitation programs commencing early in the awakening phase of critical illness and ICU hospitalization that incorporate psychological, mental health services need to be implemented in the continuum of care within and beyond ICU [18] along with speech pathology. Clinical care pathways addressing and improving physical, mental and cognitive sequelae of critical illness and ICU hospitalisation need to be established.

The findings in this study about communication difficulties are not new $[2,7,24]$. More needs to be done to find more effective ways of communicating with critically ill mechanically ventilated patients. It is important to establish effective communication for the ICU patients as that is their way of relating with others and beingin-the world. Although the importance of and the need for more models of communication have been extensively recommended elsewhere [27], more use of communication aids such as charts, communication boards and writing pads could improve communication [31]. Routine assessment by a speech therapist of individual patients' communication capability and consequent needs before leaving ICU and beyond would also help inform restorative functional activities and the provision of appropriate communication aids. Nurses' communication skills could be improved through ongoing education and practice development activities. This would be especially useful for new graduates who may be inexperienced in communicating with intubated patients [3]. Technological solutions such as computer generated voice devices $\left(\right.$ LifeVoice $^{\mathrm{TM}}$ ) are needed as they have proved beneficial elsewhere [31].

The problem of sleep deprivation remains a concern. Bearing in mind that this is a multifaceted problem [32], a holistic individualised approach would include review of medications, psychological assessment and selecting drugs that do not interfere with sleep. Patients also need to be educated about the side effects of some drugs that may cause sleep deprivation. Psychological counselling 
may be helpful for patients suffering from nightmares and routine assessment for and treatment of post traumatic stress disorder would be beneficial.

\subsection{Implications for Education}

More education and awareness of post critical illness and ICU-sequelae and their management for all involved in caring for this patient population is needed. Intensivists, nurses, general practitioners and other allied health including family and other care givers in the community often have very limited knowledge of the impact of critical illness. Such knowledge and awareness will empower all stakeholders to transition critical illness and ICU survivors from acute settings to the community and improving the quality of life for survivors.

\subsection{Implications for Research}

More research to do with the experience of critically ill patients in the context of DSI and other ICU practices including technological advancement is needed so that the future of ICU care can be guided by both the gnostic and the pathic hand that aim at not only healing the physiology and anatomy but at reuniting the patient both to their world and themselves. However, the ambiguity of technology needs to be born in mind so that demonising of technology and prioritizing of attention is not negated in critical times but is executed with thoughtfulness and tact.

Researchers need to turn their attention to strategies that examine methods and processes that can reduce the impact, particularly the longer term impact of the experience. Most importantly research and funding is needed to increase awareness of critical illness and ICU survivorship sequelae and facilitate a better survivorship experience of critical illness beyond ICU [18]. The fact that some nurse led rehabilitation clinics have not made much difference [33], implies that more research in this area is needed. The findings about continued loss or changed voices and loss of past memories call for more qualitative research particularly phenomenological research that would provide more understanding and insight into this kind of lived experience and what it means for those that go through it.

\subsection{Conclusion}

The main aim of this study was to explore and understand the experience critical illness and ICU hospitalisation in the context of DSI. Although this was a single centre study in the Australian context, it serves to stimulate further interest, discussion and desire to improve patient outcomes in ICU through practice and research at local, national and international levels. Because this is a phenomenological study, it is hoped that it has challenged clinicians to treat patients as individuals with unique and ongoing needs resulting from their critical illness and ICU hospitalization.

\section{REFERENCES}

[1] Kinrade, T., Jackson, A.C. and Tomnay, J.E. (2009) The psychosocial needs of families during critical illness: Comparison of nurses' and family members' perspectives. Australian Journal of Advanced Nursing, 27, 82-88.

[2] Urden, L.D., Stacy, K.M. and Lough, M.E. (2006) Thelan's critical care nursing diagnosis and management. 5th Edition, Mosby, Missouri.

[3] Parker, V. (1997) Confronting life and death: Living through critical illness and intensive care hospitalisation. The University of Newcastle, Newcastle.

[4] Caroll, S.M. (2007) Silent, slow lifeworld: The communication experience of nonvocal ventilated patients. Qualitative Health Research, 17, 1165-1177. doi:10.1177/1049732307307334

[5] Wang, K.F., Zhang, B., Li, C.Y. and Wang, C. (2008) Qualitative analysis of patients' intensive care experience during mechanical ventilation. Journal of Clinical Nursing, 18, 183-190. doi:10.1111/j.1365-2702.2008.02518.x

[6] Adamson, H., Murgo, M., Boyle, M., Kerr, S., Crawford, M. and Elliott, D. (2004) Memories of intensive care and experiences of survivors of a critical illness: An interview study. Intensive and Critical Care Nursing, 20, 257-263.

[7] Coyer, M.F., Wheeler, K.M., Wetzig, M.S. and Couchman, A.B. (2007) Nursing care of the mechanically ventilated patient: What does the evidence say? The Journal of Intensive and Critical Care Nursing, 23, 71-80. doi:10.1016/j.iccn.2006.08.004

[8] Kress, J.P., Pohlman, A.S., O’Connor, M.F. and Hall, J.B. (2000) Daily interruption of sedative infusions in critically ill patients undergoing mechanical ventilation. New England Journal of Medicine, 342, 1471-1477. doi:10.1056/NEJM200005183422002

[9] Wunsch, H. and Kress, J.P. (2009) A new era for sedation in ICU patients. Journal of the American Medical Association, 301, 542-544. doi:10.1001/jama.2009.24

[10] Kress, J.P. and Hall, J.B. (2006) Sedation in the mechaniccally ventilated patient. Journal of Critical Care Medicine, 34, 2541-2546. doi:10.1097/01.CCM.0000239117.39890.E3

[11] Hall, J.B. (2010). Creating the animated intensive care unit. Critical Care Medicine, 38, S668-S675. doi:10.1097/CCM.0b013e3181f203aa

[12] Kress, J.P., Gehlbach, M.L., Pliskin, N., Pohlman, A.S. and Hall, J.B. (2003) The long-term psychological effects of daily sedative interruption on critically ill patients. American Journal of Respiratory and Critical Care Medicine, 168, 1457-1461. doi:10.1164/rccm.200303-455OC

[13] Drennan, K., Hicks, P. and Hart, G.K. (2008) In- tensive care resource and activity: Australia and New Zealand 2009/2010. Centre for Outcome and Resource Evaluation 
(CORE).

http://www.anzics.com.au/core/reportsaccessed25/11/201

[14] Elliott, D., McKinley, S., Alison, J., King, M., Aitken, L.M., et al., (2011) Health-related quality of life and physical recovery after a critical illness: A multi-centre randomised controlled trial of a home-based physical rehabilitation program. Critical Care, 15, R143. doi:10.1186/cc10265 http://ccforum.com/content/15/3/R142Accessed17/10/201 1

[15] Khan, J.M., Benson, N.M., Appleby, D., Carson, S.S. and Iwashyna, T.J. (2010) Long-term acute care hospital utilisation after critical illness. Journal of the American Medical Association, 303, 2253-2259. doi:10.1001/jama.2010.761

[16] Wiencek, C. and Winkelman, C. (2010) Chronic critical illness: Prevalence, profile and pathophysiology. Advanced Critical Care Nursing, 21, 44-61.

[17] Desai, S.V., Law, T.J. and Needham, D.M. (2011) Longterm complications of critical care. Critical Care Medicine, 39, 371-379. doi:10.1097/CCM.0b013e3181fd66e5

[18] Needham, M.D., Feldman, D.R. and Kho, M. (2011) The functional costs of ICU survivorship: Collaborating to improve post-ICU disability. American Journal of Respiratory and Critical Care Medicine, 183, 962-964.

[19] Elliott, D., Mudaliar, Y. and Kim, C. (2004) Examining discharge outcomes and health status of critically ill patients: Some practical considerations. Intensive and Critical Care Nursing, 20, 366-377. doi:10.1016/j.iccn.2004.07.001

[20] Ringdal, M., Plos, K., Örtenwall, P. and Bergbom, I. (2010) Memories and health related quality of life after intensive care: A follow-up study. Critical Care Medicine, 38, 38-44. doi:10.1097/CCM.0b013e3181b42909

[21] van Manen, M. (1990) Researching lived experience: Human science for an action sensitive pedagogy. State University of New York Press, Albany.

[22] Merleau-Ponty, M. (1962) Phenomenology of perception. Routledge \& Kegan Paul Ltd., London and New York.

[23] Almerud, S., Alapack, R.J., Fridlund, B. and Ekebergh, M. (2007) Of vigilance and invisibility_Being a patient in technological intense environments. Nursing in Critical Care, 13, 151-158. doi:10.1111/j.1478-5153.2007.00216.x

[24] Zeilani, R. and Seymour, J.E. (2010) Muslim women's experiences of suffering in Jordanian intensive care units:
A narrative study. Intensive and Critical Care Nursing, 26, 175-184. doi:10.1016/j.iccn.2010.02.002

[25] Löf, L., Berggren, L. and Ahlstrom, G. (2008) ICU patients' recall of emotional reactions in the trajectory from falling critically ill to hospital discharge: Follow-ups after 3 and 6 months. Intensive and Critical Care Nursing, 24, 108-121. doi:10.1016/j.iccn.2007.08.001

[26] Samuelson, K.A.M. (2011) Unpleasant and pleasant memories of the intensive care in adult mechanically ventilated patients-Findings from 250 interviews. Intensive and Critical Care Nursing, 27, 76-84. doi:10.1016/j.iccn.2011.01.003

[27] Almerud-Österberg, S. (2010) Visualism and technification-The patient behind the screen. International Journal of Qualitative Studies on Health and Well-Being, 5, 5223.

[28] Happ, M.B., Harrington, C. and Kluger, M. (2006) Nonspeaking older adults in the ICU. American Journal of Nursing, 106, 30.

[29] Capuzzo, M., Bertaccchini, S., Davanzo, E., Glovanna, F., Paparella, L. and Tadini, L. (2010) Health-related quality of life before planned admission to intensive care: Memory over three and six months. Health and Quality of Life Outcomes, 8, 103. doi:10.1186/1477-7525-8-103

[30] Weinert, C. and Sprinkle, M. (2008) Post ICU conesquences of patient wakefulness and sedative exposure during mechanical ventilation. Journal of Intensive Care Medicine, 34, 82-90. doi:10.1007/s00134-007-0829-2

[31] Beraldo, P.S.S. (2009) Rehabilitation in patients admitted to intensive care. British Medical Journal, 339, 982-983. doi:10.1136/bmj.b3921

[32] Happ, M.B., Garrett, K., DiVirgilio, D., Thomas, M., Tate, J., George, E., et al. (2011) Nurse-patient communication interactions in the intensive care unit. American Journal of Critical Care, 20, e28-e40. http://www.ajcconline.org,Accessedon12/04/2011

[33] Tembo A. C and V, P. (2009) Factors that impact on sleep in intensive care patients. Intensive and Critical Care Nursing, 25, 314-322. doi:10.1016/j.iccn.2009.07.002

[34] Cuthbertson, B.H., Rattray, J., Campbell, M.K., Gager, M., Roughton, S., Smith, A., et al. (2009) The practical study of nurse led, intensive care follow-up for improving long term outcomes from critical illness: A pragmatic randomised controlled trial. British Medical Journal, 339, b3723. doi:10.1136/bmj.b3723 